\title{
TRAINING ASPIRING ENTREPRENEURS TO PITCH EXPERIENCED INVESTORS: EVIDENCE FROM A FIELD EXPERIMENT IN THE UNITED STATES *
}

\author{
David Clingingsmith ${ }^{1}$ \\ Scott Shane ${ }^{2}$ \\ Weatherhead School of Management, \\ Case Western Reserve University
}

June 2017

${ }^{1}$ Email: dlc43@,case.edu. Tel: 216-368-5538. Address: 11119 Bellflower Road, Cleveland, Ohio 44106.

${ }^{2}$ Corresponding author. Email: sas46@case.edu. Tel: 216-368-5538. Address: 11119 Bellflower Road, Cleveland, Ohio 44106.

* The authors would like to thank the Burton D. Morgan Foundation for the financial support that made this research possible. They would also like to thank Jay Barney, Chuck Eesley, Riita Katila, Silke Forbes, Sabrina Howell, Nico Lacetera, Josh Lerner, Melissa Schilling, Antoinette Schoar, Matt Sobel, Scott Stern, Mark Votruba, Batia Wiesenfeld, and Todd Zenger for their helpful comments. Seminar participants at Case Western Reserve University, New York University, Stanford University, the University of Utah, and the 2016 NBER Summer Institute provided useful comments. Eoghan Bees, Laura Mummey, Cameron Crosby, Mary Kate O'Conner, Raechel Boyko, Jered Tyler, Jazmine Kirtland, John Tarchick, Sophia Chan, Joey Johnson, Victoria Sung, Julio Ayala, Oliver Ruhl, Natasha Smith, Reeny John, Zack Tobias, Sarah Ronan, and Ryan Cleary provided invaluable research assistance. 


\title{
TRAINING ASPIRING ENTREPRENEURS TO PITCH EXPERIENCED INVESTORS: EVIDENCE FROM A FIELD EXPERIMENT IN THE UNITED STATES
}

\begin{abstract}
Accredited investors finance more than 75,000 U.S. start-ups annually. We explain how training aspiring entrepreneurs to pitch their new business ideas to these investors affects their odds of continued funding discussions. We model accredited investors' decision to continue investigation as a real option whose value is a function of their experience and the information contained in the entrepreneurs' pitches. We derive four hypotheses from the model, which we test through a field experiment that randomly assigns pitch training at four elevator pitch competitions. The data support all four hypotheses, and are inconsistent with alternative explanations.
\end{abstract}

Keywords: pitching, start-ups, investment, training, experiment

JEL Codes: M13, D8, G29, C93 
If you are an entrepreneur, you have less than 60 seconds to get an investor's attention.

--Brad Feld (2012), Managing Director of the Foundry Group and Founder of TechStars accelerator. ${ }^{1}$

Entrepreneurs often try to attract potential investors with a short verbal introduction to their businesses called an "elevator pitch" (Getty 2005; Clark, 2008). The pitch, usually less than two minutes in length, provides an initial glimpse of the venture idea ${ }^{2}$ with the goal of engaging the investor in further conversation and, ultimately, obtaining financing.

Because many entrepreneurs and investors think that elevator pitches are important, the Internet is replete with examples of those used by the founders of well-known start-ups, such as Airbnb, Uber, and Mint.com. In YouTube videos and blog posts, prominent entrepreneurs and investors recount stories of how a brand-new start-up's initial pitch was the first step to raising millions of dollars, and allowed a team with little more than an idea to begin building a billion-dollar company. ${ }^{3}$

Universities and startup accelerators have institutionalized elevator pitching. Hundreds of U.S. universities hold elevator pitch competitions every year. Collectively, the winners of these competitions have gone on to raise billions of dollars in financing. ${ }^{4}$ Many startup accelerators provide elevator pitch training and feature "demo days" where graduating entrepreneurs pitch their businesses to investors. Finally, elevator pitch training is part of entrepreneurship classes from the high school through the MBA level.

\footnotetext{
${ }^{1}$ The Foundry Group is a leading venture capital firm based in Boulder, CO. TechStars is a global network of accelerator programs.

${ }^{2}$ We use the term "idea" in this paper to refer to the entrepreneur-business concept combination. Because investors must consider the package of the team and the business concept together (they cannot pick one team and another concept), we treat them as a singular unit in our study and refer to the combination using the term "idea".

${ }^{3}$ These prominent examples are only the very tip of a very large iceberg. Every year more than 75,000 start-up businesses receive outside equity investment in the U.S. alone. Wealthy individuals who invest their own capital, known as business angels, account for most of these investments. There were 304,930 active angel investors in 2015, and they invested \$24.6B in 71,110 companies in 2015 (Center for Venture Research 2015). ${ }^{3}$ Smaller in number, though with larger average deal size, are the venture capital firms. There were 718 venture capital firms in 2015 . They invested \$59.1B in 3,709 companies (National Venture Capital Association 2016).

${ }^{4}$ For example, Jenn Hyman pitched the concept of Rent the Runway at an NYU pitch competition in 2010, https://vimeo.com/19591994. Her company has gone on to raise $\$ 114.4$ million in five rounds from ten investors.
} 
Given the importance of pitching, a robust practitioner literature has emerged to describe pitching "best practice," i.e. the way that practitioners collectively believe pitching should occur (Coughter 2012; Getty, 2014; Klaff, 2011; McGowen, 2015; and Soorjoo, 2012). In addition, many leading investors have posted articles and presentations online to provide advice on how to prepare an effective elevator pitch. ${ }^{5}$

These developments might suggest that academic researchers have identified the key dimensions of effective pitching and how best to teach those things. However, for at least two reasons, the existing body of work on pitching does not provide convincing evidence on these issues (Mason and Harrison 2003, Foo, Wong, and Ong 2005; Grégoire et al 2008, Chen et al 2009, Maxwell et al 2011, Nagy et al 2012, Parhankangas and Ehrlich 2014; Coughter 2012, McGowan 2014; Clark, 2008).

First, researchers lack knowledge of the true causes of pitch performance. While the experimental method is best suited to measuring causal effects, most studies of pitching are anecdotal or use observational data. No randomized experiments have thus far explored the value of pitch training on efforts to attract equity investors.

Second, the practitioner literature generally assumes that pitch training will improve an entrepreneur's chance of interesting an investor in their idea. However, this assumption is likely to be incorrect. Pitch training focuses on the delivery of useful information about the venture idea and the people pursuing it. It is not a tool to improve the venture idea itself.

We argue that pitch training helps entrepreneurs to convey their ideas more accurately, thereby enabling investors to better distinguish between good and bad ideas. Pitch training is therefore welfare-enhancing to investors and entrepreneurs with high quality ideas, but, at least in the short run, not to entrepreneurs with low quality ideas.

\footnotetext{
${ }^{5}$ Examples include Dave McClure, http://www.slideshare.net/dmc500hats/how-to-pitch-a-vc-or-angel-13504703; Richard Branson https://www.virgin.com/entrepreneur/richard-branson-this-is-what-they-mean-by-an-elevator-pitch; Bill Reichart https://www.gsb.stanford.edu/insights/bill-reichert-venture-capitalist-offers-tips-pitching-your-start; Mark Suster https://bothsidesofthetable.com/how-to-nail-the-elevator-pitch-f4a790ce5466\#.atmrcfxj7; and Brad Feld, $\quad$ http://www.feld.com/archives/2012/10/if-you-cant-explain-what-you-do-in-a-paragraph-youve-got-aproblem.html
} 
We develop a simple model that begins with the assumption that pitch training makes entrepreneurs better at conveying their ideas to investors, who treat the decision to further investigate an idea as a real option. We test the predictions of the model with a field experiment in which we randomly assigned participants in four elevator pitch competitions to either a training or null treatment and then to a panel of judges.

Prior research does not consider how an important investor characteristic_experience—influences receptiveness to pitches. However, the practitioner literature (e.g., Rose, 2014) has long noted that experienced and inexperienced ${ }^{6}$ early-stage investors behave very differently. Our model recognizes that investor experience influences the expectations ("priors") investors have about ventures, and that this, in turn, influences the effectiveness of pitching and pitch training.

Our results show that pitch training affects pitch performance in ways consistent with our model, but not with alternative explanations. Training increased the use of best-practices elements in pitching by about one third of a standard deviation. It had a positive effect on experienced investors' evaluation of highquality pitches, but negative effects otherwise. Pitch training helps investors to distinguish between high and low quality venture ideas more efficiently, which means it is more valuable to entrepreneurs with high quality ideas than those with low quality ones. These results have normative implications for how to train aspiring entrepreneurs to pitch experienced investors.

\subsection{THEORY}

The venture investor's decision process has been likened to finding a needle in a haystack. There are a large number of new ventures seeking funding but only a small number of them will ever produce excess returns. Early stage investment thus provides the possibility of receiving enormous profits from successful

\footnotetext{
${ }^{6}$ We will describe how we measure experienced and inexperienced investors in the methodology section of the paper. However, our conceptual definition is as follows: Experienced investors are ones that make enough early stage investments to have private information about the distribution of quality of early stage companies, while inexperienced investors are ones that do not make enough early stage investments to have private information about the distribution of quality of early stage investments.
} 
choices (Huang and Pearce, 2015), but, even after winnowing out the vast majority of opportunities presented to them, 90 percent of the companies that investors actually fund result in complete losses of their capital (Rose, 2014). Therefore, in making their decisions, investors seek to balance the opportunity to make enormous profits from backing a "home run" with the likelihood that any given venture they fund will do little more than lose their capital (Huang and Pearce, 2015).

This problem is far from trivial. Investors will back a handful of the ventures that entrepreneurs pitch to them, and will do so only after spending considerable time investigating those investment opportunities. At the same time, the practitioner literature is rife with examples of investors who saw pitches for companies like Facebook, Google, and Apple Computer, but chose to pass on further investigation. The pattern of returns leads investors to evaluate ventures in stages, allowing a larger number of entrepreneurs to initially make brief presentations, but seeking subsequent meetings to gather additional information from only a small fraction of them (Carpentier and Suret, 2015; Maxwell et al, 2011). At each stage of the investigation process, investors sort ventures into those for which they will devote an increasing amount of time to investigate, and those that are winnowed out (Clark, 2008). Each stage of this process is akin to purchasing a real option. The option allows an investor to make a subsequent decision to continue investigating or to stop after having learned some additional information.

At the very beginning of the process, a given venture has very low odds of continuing discussions with an investor, let alone receiving financing. These low initial odds mean that investors limit the amount of time they will spend hearing about the venture idea. Typically, an investor will listen only to a very short pitch (or read a very short description of the venture) before making a first decision about whether to continue or terminate investigation (Maxwell et al, 2011). If the initial reaction is negative, the entrepreneur will have lost his or her opportunity to raise money with that investor.

We focus our attention on this very first stage of entrepreneurs' fund raising efforts - the elevator pitch. Because this pitch must be very short, it cannot generally provide a complete account of a venture idea (Maxwell et al, 2011). For this reason, investors rarely choose to invest in a new business solely on the basis of an elevator pitch. The purpose of the pitch is to motivate investors to continue the discussion in a 
more substantial way, such as through a further meeting or through the investor's review of a business plan or "pitch deck" (Getty 2005; Clark, 2008). After listening to an elevator pitch, investors make a decision to either seek more information about the venture or cease consideration of the idea. The decision to progress or not is generally made without independent investor research (Clark, 2008).

\subsection{The Investor's Elevator Pitch Decision and the Real Option to Invest}

Our experiment investigates the first decision point following the investor's initial introduction to a venture via an elevator pitch. Figure 1 presents a decision tree for an investor who considers how to invest a discrete amount of capital $k$. We suppose that the return to entrepreneurial ventures is given by a random variable $R$ that follows the density $f(R)$. The decision process begins with viewing an elevator pitch, which generates a noisy signal $s$ of the true quality of the venture $r$. The signal $s$ is a realization of the random variable $S$ that has distribution $g(S)$ and for which $E(g(S))=r$.

After receiving the signal $s$, the investor faces the first decision. He or she either spends an amount $z$ to further investigate the venture by undertaking due diligence or discontinues investigation and invests in a default project that has expected returns $\tilde{r}>k .^{7}$ Due diligence provides information about the true return $r$ to the venture that was pitched. Note that in reality there may be many points at which an investor may choose whether to continue investigating. We examine only a single decision because it matches the structure of our experiment. Following due diligence, the investor faces a second decision in which he or she chooses between investment in the venture or the default project.

The investor seeks to maximize the value of his or her investment. The value at the first decision $V_{1}$ is the maximum of the net return to the outside investment and the expected value of the second decision $V_{2}$ given the information $s$ provided by the signal,

$$
V_{1}=\max \left\{\tilde{r}-k, E\left(V_{2} \mid s\right)\right\}
$$

\footnotetext{
${ }^{7}$ We allow the investor to compare a single draw from $f(R)$ to a default option rather than allowing the pitch process to recur with additional draws and terminate with investment in one of them. This both simplifies the problem and more closely matches our experiment, where the number of pitches considered is fixed in advance.
} 
If the investor has chosen to advance to the second decision, he or she pays $z$ and learns $r$. In the second decision, he or she chooses between the venture and the default investment. The value at the second decision is the maximum of these two alternatives

$$
V_{2}=\max \{\tilde{r}, r\}-z-k
$$

We can simplify $V_{1}$ by substituting in $V_{2}$ and rearranging to get

$$
V_{1}=\max \{\tilde{r}-k, E(\max \{\tilde{r}, r\}-z-k \mid s)\} .
$$

We define the option value of proceeding to due diligence $v(s)$ as the difference in expected return between purchasing and not purchasing the option at the point of the first decision.

$$
v(s)=E(\max \{\tilde{r}, r\}-z-k \mid s)-(\tilde{r}-k) .
$$

We can also write $v(s)$ as

$$
v(s)=(\tilde{r}-z-k) \int_{-\infty}^{\tilde{r}} f(R \mid s) d R+\int_{\tilde{r}}^{\infty}(R-z-k) f(R \mid s) d R-(\tilde{r}-k) .
$$

The first term reflects the return earned by the investor when due diligence reveals the venture to be worse than the default investment and the option to invest is not exercised. The value of the first integral is just the probability that $R<\tilde{r}$. The second term reflects returns earned when due diligence reveals the venture to be better than the default investment and the option to invest in it is exercised, and the third term subtracts the net return received if the investor decides not to proceed to due diligence.

We can use Bayes theorem to rewrite $v(s)$ in terms of the distributions $f(R)$ and $g(S \mid r)$ as follows

$$
v(s)=(\tilde{r}-z-k) \int_{-\infty}^{\tilde{r}} \frac{g(S \mid r) f(R)}{\int g(S \mid r) f(R) d R} d R+\int_{\tilde{r}}^{\infty}(R-z-k) \frac{g(S \mid r) f(R)}{\int g(S \mid r) f(R) d R} d R-(\tilde{r}-k) .
$$

\subsection{Pitch Training, Investor Experience, and Option Value}

In order to use equation 1 in the analysis of our pitch training experiment, we must specify how pitch training affects the pitch signal $g(S \mid r)$. Our pitch training intervention was designed to increase the number 
of information elements $\ell$ that entrepreneurs included in their pitches. We assume that $\ell$ affects the precision of the pitch signal $s$ but not the venture's expected value. This assumption captures the fact that pitch training is about what kinds of information to present and how to present them and not about developing the venture idea itself. (We recognize that other types of entrepreneurship training may affect the value of the idea itself.) We assume that the pitch signal is normally distributed with its mean at the true return $r$ and with precision proportional to the number of elements $\ell$ in the pitch

$$
g(S \mid r)=N\left(r,(\lambda \ell)^{-1}\right)
$$

where $\lambda>0$ is a scaling parameter and $r$ is the true return, which is unknown to the investor. We assume that all pitches have at least one element so that the signal variance is finite. We make the testable assumption that pitch training increases $\ell$, which thereby increases the precision of the signal $s$.

To analyze how pitch training affects the value of due diligence $v(s)$ using equation 1 , we need to compute the posterior distribution of $R$, which requires additional structure on $f(R)$. We assume that the true distribution of returns is standard normal $N(0,1)$. Although investors may not have completely accurate priors about the true distribution, we assume they have the prior belief that the distribution of true returns is normal with mean zero and precision $p$,

$$
f(R)=N\left(0, p^{-1}\right)
$$

In other words, all investors have correct beliefs about the mean return to investments in new ventures, but may have incorrect beliefs about the variance. Note that a belief about the precision $p$ is equivalent to a belief about the probability $q$ that a venture returns more than the default investment because, given this distribution, there is a one-to-one relationship between $q$ and $p .^{8}$

${ }^{8} q=1-\operatorname{Erfc}\left(-\frac{p \tilde{r}}{\sqrt{2}}\right)$ where $\operatorname{Erfc}(x)=\frac{2}{\sqrt{\pi}} \int_{x}^{\infty} e^{-t^{2}} d t$ is the complementary error function. 
Investors differ in the duration of experience they have had in investing in entrepreneurial ventures, which has implications for how they value venture ideas. We will label experienced investors $E$ and novice investors $N$. We assume that experienced investors are less likely to believe that a venture will return more than the default, or that $q_{E}<q_{N}$. In other words, they believe the upside potential of a randomly selected venture is lower than inexperienced investors believe it to be. Experienced investors also have more precise priors than inexperienced investors $p_{E}>p_{N}$, as a result of learning that outcomes take longer to realize than inexperienced investors believe. Note that these differences between experienced and inexperienced investors imply experienced investors believe there are fewer outcomes in the upper tail of the distribution, where the option value of due diligence is positive.

Since both the likelihood $g(S \mid r)$ and prior $f(R)$ are normally distributed and the normal distribution is self-conjugate, the posterior density is normal with the following parameters

$$
f(R \mid s)=\frac{g(S \mid r) f(R)}{\int g(S \mid r) f(R) d R}=\phi\left(\frac{s \lambda \ell}{p+\lambda \ell}, \frac{1}{p+\lambda \ell}\right)
$$

where $\phi(\cdot, \cdot)$ is the normal density function. Note that the mean of the posterior density is the precisionweighted average of the prior mean of 0 and the pitch signal $s$. We can therefore write

$$
v(s, p, \ell, \tilde{r})=(\tilde{r}-z-k) \int_{-\infty}^{\tilde{r}} \phi\left(\frac{s \lambda \ell}{p+\lambda \ell}, \frac{1}{p+\lambda \ell}\right) d R+\int_{\tilde{r}}^{\infty}(R-z-k) \phi\left(\frac{s \lambda \ell}{p+\lambda \ell}, \frac{1}{p+\lambda \ell}\right) d r-(\tilde{r}-k) .
$$

We solve the integrals in equation 2 in Appendix A to get equation A2, an expression for option value of due diligence as a function of the signal $s$ and parameters $p, \ell, \lambda$, and $\tilde{r}$. We use equation A2 to predict the effect of differences in investor priors, pitch training, and returns to the default investment on the option value of a particular idea.

We derive and present four main results. We provide an intuitive explanation of each result here, and proofs in Appendix A. In the following section, we use these results to generate testable hypotheses for our experiment. 
Result 1. Option value $v(s)$ is increasing in pitch elements $\ell$ for pitch signals above a threshold $\bar{s}$ and decreasing in pitch elements $\ell$ for pitch signals below $\bar{s}$.

In mathematical terms, $\frac{\partial v}{\partial \ell}<0$ for $s<\bar{s}$ and $\frac{\partial v}{\partial \ell}>0$ for $s>\bar{s}$. Intuitively, increasing the number of elements increases the precision of the pitch signal. If venture quality is high, increasing precision increases the investor's posterior belief that the venture will return more than the default option, and the option value will go up. Conversely, if venture quality is low, increasing precision will reduce the likelihood that the venture will return more than the default investment and the option value will fall. Figure 2 plots the partial derivative $\frac{\partial v}{\partial \ell}$ and values of $\bar{s}$ for some plausible parameter values. Three different curves correspond to different levels of prior precision. The analysis in Appendix A shows that $\bar{s}$ is in the upper tail of the distribution of $s$ for plausible parameter values.

Result 2. The threshold $\bar{s}$ is decreasing in the prior precision $p$ and increasing in the default return $\tilde{r}$.

The threshold $\bar{s}$ at which the effect of additional elements switches from negative to positive falls as prior precision $p$ increases and rises as the default return $\tilde{r}$ increases. The relationship between $\bar{s}$ and prior precision $p$, relevant for our discussion of investor experience, is illustrated in Figure 2.

Result 3. Option value $v(s)$ is decreasing in the precision of the investor's prior $p$.

Recall that the prior mean is zero and that the investment cost $k$ and default return $\tilde{r}$ are positive. This means that when the prior precision rises, the posterior mean falls, reducing the posterior probability that a particular idea has a return greater than $\tilde{r}$ and a positive option value.

Result 4. Option value $v(s)$ is decreasing in the default return $\tilde{r}$.

The option value can be thought of as the expected upside from spending $z$ to conduct due diligence. When the default investment has a higher return, it is less likely that the pitched venture will be better than the default return $\tilde{r}$, which makes doing diligence less valuable. 


\subsection{Hypotheses}

The model results suggest a set of hypotheses about how pitch training will affect the scores that judges assigned to participants in our experiment. After hearing a pitch, our judges were asked to evaluate the likelihood that they would further investigate the idea in four different ways. We aggregate their responses into a score. The score corresponds to the option value of due diligence analyzed in the model.

Our first hypothesis is that that pitch training increases the number of elements contained in pitches. Our pitch training program was explicitly designed to increase the elements participants included in their pitches based on the findings of the practitioner literature. Therefore, we expect that the subjects would respond to the training as designed and add elements to their pitches.

Hypothesis 1: Training increases the number of elements contained in the pitches.

Our second hypothesis concerns inexperienced and experienced investors. Result 3 showed that experienced investors will give lower scores to a given pitch than inexperienced investors. Recall that we assumed experienced investors have greater prior precision, either because they have learned that outcomes take a longer time to occur than novice investors believe or because they think it is less likely that a venture will return more than the default. Greater prior precision means experienced investors are less likely to think that any particular venture will return more than their default investment because greater prior precision gives less weight to the signal in the posterior. Because experienced investors are less likely to think that any particular venture will return more than their default investment, they are less likely to engage in further due diligence. As a result, experienced investors will give lower scores (which measure their interest in investigating the venture further) to any particular venture than inexperienced investors.

Hypothesis 2: Experienced investors will give lower scores to a given pitch than inexperienced investors.

The third hypothesis concerns the effect of pitch training on the scores of ventures of different levels of quality. Result 1 showed that increasing elements has an effect on option value that switches from negative to positive at a threshold $\bar{s}$. This means that providing more elements in a pitch is beneficial when 
the quality of the venture idea is above the threshold, but not below it. Because training induces entrepreneurs to increase the number of elements in their pitches, the value of training is thus greater when the venture is of higher quality. We therefore predict that training will have a more positive effect at higher quantiles of the quality distribution than at lower ones and will thereby increase the variance of scores.

Hypothesis 3: Training will have a more positive effect on upper quantiles of the quality distribution than lower quantiles and will therefore increase the variance of scores.

Since $\bar{S}$ is in the upper tail of the distribution, the model further suggests that training will have a negative effect on most ventures, and that, to the extent the effect of training on elements is constant, the average effect may be negative.

As we have explained, pitch training increases the precision of the signal about venture quality. Increasing the signal precision increases degree to which the investor will rely on it relative to his or her prior beliefs about ventures in general. How this signal affects the value of due diligence depends on the venture's quality. If venture's quality is low, greater precision increases the investor's confidence that the venture actually will have a low return, and makes the option of proceeding to due diligence less valuable. Similarly, if venture's quality is high, greater precision increases the investor's confidence that the venture will have a high return, and makes the option of proceeding to due diligence more valuable.

Experienced investors have greater prior precision $p$ because they have a better understanding of the time it takes for ventures to achieve a positive or negative outcome and a more accurate sense of the magnitude of the upside of the most successful ventures. According to Result 4 and as illustrated in Figure 2, this implies that the level of $\bar{s}$ is lower for experienced investors than inexperienced investors. Therefore, all levels of $s$, the effect of the entrepreneur providing additional elements in the pitch is more positive for experienced investors than inexperienced ones.

Hypothesis 4: Training has a more positive effect on experienced investors than inexperienced investors at all score levels. 


\subsection{METHODS}

We conducted a field experiment at elevator pitch competitions to test our hypotheses. In elevator pitch competitions, entrepreneurs deliver short pitches to judges to win prize money. Pitch competitions are a popular way for younger entrepreneurs to gain experience at pitching, and hundreds are held annually across the United States (Brooks et al, 2014). We ran four competitions at Northeast Ohio universities in the fall of 2015. Participants had 90 seconds to present their own original business idea. The competitions ran from 9 a.m. to 4 p.m. on a Saturday. Each of the competitions had identical prize money: first place was $\$ 2,500$, second place was $\$ 1,000$, and third place was $\$ 500$.

\subsection{Experimental Design and Procedures}

Participants signed up in advance using an online tool. They agreed to be randomly assigned to five different training treatments. The training was delivered by video. Random assignment to treatment was stratified by gender and prior experience pitching. Information on these variables was collected at sign-up.

All five treatments explained the purpose of an elevator pitch. ${ }^{9}$ Four of treatments provided detailed training on how to pitch to investors. ${ }^{10} \mathrm{We}$ call these treatments pitch training. The pitch training treatments varied in the aspects of pitching emphasized and the use of illustrative examples. The fifth treatment provided training on venture finance without any information on pitching. We call this treatment the null. Table 1 shows the types of training. In this study, we have collapsed the treatments into two categories: pitch training and null. Participants in the null category were given minimal training about pitching, while those in the pitch training category were given detailed training about pitching.

Participants were also randomly assigned to a panel of judges to whom they would give their pitch and to a place in the order of pitching for that panel. The random assignment of both training and judges allows

\footnotetext{
${ }^{9}$ We explained the basic purpose of an elevator pitch to all participants because we expected some participants to have no experience with the process of funding a business venture.

${ }^{10} \mathrm{We}$ pool the training because each type of pitch training in one dimension of best practices should improve the performance of entrepreneurs at pitching relative to no training in any of the dimensions of "best practice."
} 
us to test hypotheses that contrast the responses of experienced and inexperienced judges to the training treatment.

When they arrived at competition, participants checked in and were directed into a holding room where they completed a demographic survey. Once check-in was complete, each participant was randomly assigned a treatment group, judge panel, and place in the pitch order. Each treatment group had a facilitator that stayed with the group throughout the day. The facilitator assembled the participants in his or her group and led them to a separate training room.

Once in the training room and settled, the participants wrote a first draft of their elevator pitch. They were reminded that pitches were limited to 90 seconds and were to be delivered without props, notes, or slides. Participants had 15 minutes to write their drafts. The drafts were collected for copying.

The participants then received 30 minutes of video-based training. Each training video was presented by the same actor. Six main topics, covering either pitch content or pitch style, were covered in each of the pitch training treatments. The content topics were identification of a customer need; the venture's value proposition; the venture's market; the entrepreneur's expertise in this domain; competitive advantage; and the deal for investors. The style topics were use of narrative; engagement with the audience; attractive framing of ideas; evidence of preparation; clarity; and good communication style. Three basic elements common to all treatments were identification of a key message, motivating the investor to care about the venture, and making a request for support.

The treatments that used examples had actor demonstrating key points using a pitch for a hypothetical business called Cup Ad. While the video was playing, we copied the first draft pitches to use for analysis. The originals were returned after the video was completed.

After viewing the video, participants were given a short bulleted summary of the main points covered and were asked to write a final draft of their pitch. Participants had 45 minutes to write their final draft. At the end of this period, we collected the final drafts for copying while the participants were provided with lunch. The final drafts were then returned to participants. 
The final step was to deliver the 90 second elevator pitch to a randomly assigned panel of three to four judges. Each panel was seated in a separate room. Participants were called from their training rooms in their randomly assigned order to pitch to the panel. The pitches were limited to 90 seconds using a timer. The panel asked one question of each presenter, which the presenter then answered. Upon completion of the pitch and question and answer period, the judges scored the pitch immediately. The participant was then asked to leave the area of the experiment and return later to learn the results of the competition.

The judges scored the pitches using 7-point Likert-scale questions from "strongly disagree" to "strongly agree". There were four questions: (1) "I would pursue a follow-up meeting to learn more about the venture," (2) "I would be interested in seeing the business plan for this venture," (3) "I would recommend this opportunity to a co-investor," and (4) "I would initiate due diligence on this venture." Responses were aggregated into a score that ranges from 4 to 28.

The judges were also asked to rate the content and style of the pitches with two 7 point Likert-scale questions from "very poor" to "excellent". The two items were: (1) "The content of this elevator pitch was..." and (2) "The presentation style of this elevator pitch was ..."

Judges were recruited from the Northeast Ohio entrepreneurship ecosystem. All judges were accredited investors, ${ }^{11}$ but they varied in their early stage venture finance activity. We used this information to identify those who were venture capitalists, business angels, members of investment support organizations (what we call mentors), entrepreneurs, and senior managers of large companies.

\subsection{Pitch Elements and Idea Quality}

\footnotetext{
${ }^{11}$ The Securities and Exchange Commission (SEC) defines an accredited investor as an individual with a net worth of at least $\$ 1$ million excluding his or her home or a single person with an annual income of at least $\$ 200,000$ in each of the past three years or a married couple with an annual income of at least $\$ 300,000$ in each of the past three years. The SEC defines an organization as an accredited investor if it is a bank, savings and loan association, broker dealer, insurance company, investment company, or private business development company. Most of the investors were accredited investors by virtue of the individual definition. A few were accredited investors by virtue of the venture capital firm, family office, or angel fund they represented.
} 
To measure the elements contained in the pitches, we had six undergraduate students code both the initial (pre-training) and final (post-training) drafts of the pitches. The coders did not know the identity of the participants, the treatment they had received, or whether a particular draft was an initial or final draft. The coders were asked to identify the presence or absence of six dimensions of content, six dimensions of style, and the three basic elements common to all treatments that were outlined above. We refer to these fifteen dimensions as pitch elements and compute the average number present across all coders for each participant's first and final draft. The evaluations of the presence or absence of elements was quite similar across the coders. The intraclass correlation of the average number of elements measured by the six coders was 0.82 .

To measure the overall quality of the business ideas participants chose to pitch, we had three undergraduate students who had taken and received a grade of " $\mathrm{A}$ " in an upper-level entrepreneurial finance class, and who had not coded the first and final drafts for presence of the elements, evaluate the "quality" of the ventures. The students in this class (which involved having venture capitalists, business angels, members of business accelerators, and other members of the entrepreneurship ecosystem around the country speak to them about entrepreneurial finance via telepresence) had learned from prominent angels (members of the Angel Capital Association Board) and prominent venture capitalists (partners at firms like Greylock and Sequoia Capital) the dimensions of start-up companies that are appealing to investors.

The three students each read each of the first-draft pitches and coded them for the quality of the business described using a 10-point Likert scale. In conducting their evaluation, the students were asked to apply the concepts that they had learned from prominent practitioners about what makes an attractive start-up venture and then form their own subjective evaluation.

The quality measure used in our analysis was the sum of the three evaluators' quality scores. The intraclass correlation of the average evaluations of quality of the three coders was 0.73 .

\subsection{Participant and Judge Characteristics}


We relied primarily on the survey completed by participants to obtain information about their characteristics to use in the analysis. These characteristics are described in Table 2. We additionally used internet searches to determine whether participants had been involved in an entrepreneurial venture before the competition. The sources for the additional information search included LinkedIn, company websites, and the state of Ohio's database of legal entities.

It is important to note that these measures are used largely to check our efforts to achieve randomization. The training was randomly assigned across the participants.

We developed measures of judge characteristics primarily through their LinkedIn profiles and the entrepreneurial information aggregator CrunchBase. We developed two primary measures of experience evaluating new ventures. The first measure is whether the judge has seen a high volume of early stage deals. To implement this measure, we identified the number of early-stage deals each judge had been involved in, as measured by CrunchBase, and created a dummy variable equal to one for those at or above the median. The second measure was whether the judge indicates being a venture capitalist, business angel, or a startup mentor as part of their professional identity, as indicated by their LinkedIn profile. Again, we used a dummy variable equal to one to indicate each of these characteristics.

\subsection{Data Analysis}

This section describes the regressions we use to analyze the data collected in the experiment. We measure the effect of pitch training on the elements participants include in their pitches using a regression at the participant level. Let $i$ index the participants and $p$ index the panel of judges to which a participant was assigned. The elements included in the final draft is $y_{i p}$. In the specification

$$
y_{i p}=\mu_{p}+\delta P T_{i}+X_{i}^{\prime} \theta+\varepsilon_{i p},
$$

the coefficient $\delta$ measures the effect of pitch training $P T_{i}$ on elements in the final draft. The term $\mu_{p}$ is a judge panel fixed effect. We include this fixed effect only to improve the precision of our estimates. Since participants are randomly assigned to panels, including it does not affect the estimate of $\delta$ in expectation. 
The vector $X_{i}$ contains participant level control variables, including dummy variables for the randomly assigned pitch order, and $\varepsilon_{i p}$ is an error term.

We measure the effect of pitch training on judges' scores using a regression at the judge-participant level. Let $s_{i j}$ be a score assigned by judge $j$ to the pitch delivered by participant $i$. In the following specification, the coefficient $\beta$ measures the effect of pitch training on score.

$$
s_{i j}=\alpha_{j}+\beta P T_{i}+X_{i}^{\prime} \theta+\varepsilon_{i j}
$$

The term $\alpha_{j}$ is a fixed effect that captures judge-specific variation in scoring. The vector $X_{i}$ contains participant-level control variables, including dummy variables for the randomly assigned pitch order. The term $\varepsilon_{i j}$ represents unexplained variation in scores. When we compute standard deviations for this regression, we allow for arbitrary correlation of the $\varepsilon_{i j}$ at the participant level as variation in our variable of interest $P T_{i}$ occurs at that level (Moulton 1990). ${ }^{12}$

When testing whether there is a difference in the effect of training for judges by experience level, we modify equation 6 to include an interaction between $P T_{i}$ and an experience dummy $E_{j}$. The coefficient $\beta_{E}$ in the following regression measures the differential effect of pitch training on for experienced judges.

$$
s_{i j}=\alpha_{j}+\beta_{E}\left(P T_{i} \times E_{j}\right)+\beta P T_{i}+X_{i}^{\prime} \theta+\varepsilon_{i j}
$$

Note that since the indicator $E_{j}$ is a linear combination of the fixed effects $\alpha_{j}$, a main effect for $E_{j}$ does not appear in the regression.

\subsection{RESULTS}

A total of 271 entrepreneurs from ten Northeast Ohio universities and 50 judges participated in the competitions. Table 2 provides descriptive statistics for both participants and judges. The average age of participants was 23. Most were male (68\%) undergraduates $(74 \%)$. More than half had taken courses in

\footnotetext{
${ }^{12}$ Note that while pitch training does induce random variation in final draft elements, we cannot use pitch training as an instrument for final draft elements in a regression to measure their effect on score. Although our training targeted changes to pitch elements, we cannot rule out that training also affected outcomes correlated with information but for which we do not have measures. Those outcomes would be part of the residual in a regression of score on final draft elements, which would violate the exclusion restriction for use of pitch training as an instrument.
} 
business or entrepreneurship. A third had given a pitch before. The average judge was in his late forties. Only $14 \%$ of judges were female. More than half were active venture capitalists, business angels, or mentors. All were accredited investors.

Random assignment of participants to the pitch training or null treatments ensures that the expected value of any participant characteristic will be the same, or balanced, across treatments. We stratified random assignment by gender and prior experience to mechanically ensure balance there. However, it is possible that random assignment could be unbalanced across other characteristics that might be correlated with our variables of interest. To check this possibility, Table 2 also presents means of participant's characteristics for the pitch training group and the null group and the p-value for a t-test of the null hypothesis that the mean characteristics are identical across groups. We additionally show that the pitch training balanced across judge experience characteristics for selected variables in Appendix Table B1.

We will now analyze the experiment to test the hypotheses developed in Section 2. The first two hypotheses relate to assumptions regarding the effect of training and the experience of judges.

Our first hypothesis is that pitch training will increase the elements contained in pitches. There is strong support for this hypothesis in the data. Table 3 shows the effect of training on the number of pitch elements present in the participants' final drafts. The average participant had 9.3 of 15 elements present. Note that this is not the same as saying nine separate sentences are included in the pitch. Some elements relate to the pitch as a whole, and a single sentence may show the presence of more than one element. ${ }^{13}$

Pitch training increases the number of elements by about 0.6 (column 1). Adding dummy variables for the randomly assigned pitch panel and pitch order does not affect the coefficient (column 2), nor does adding a set of controls for participant characteristics (column 3). The effect is statistically significant at the 5 percent level in all three specifications. The effect of training is about one-third of a standard deviation

\footnotetext{
${ }^{13}$ Consider the following example of part of an elevator pitch offered by Elliot Loh (2011), designer of Yammer, former $\mathrm{COO}$ of Geni, and current mentor at 500 Startups...If I had to propose a formula [for an elevator pitch], it would look something like this: We solve $<$ problem $>$ by providing $<$ advantage $>$, to help $<$ target $>$ accomplish $<$ target's goal $>$. .... We make money by charging $<$ customers $>$ to get $<$ benefit $>$. $>$." These two sentences alone include six elements.
} 
in size, which is quite large given the relatively short length of the intervention. Pitch training has a uniform effect across the quantiles of score (see Appendix Figure B1).

Note that the effects of training lie in the addition of multiple elements rather than the addition of one particular element. The effects of training on individual elements is shown in Appendix Table B2. The only negative point estimates are on those elements common to both pitch training and null training (panel A). The point estimates for all content and style elements for which some participants were randomly trained to include are positive (panels B and C). While the size of each individual effect varies, no single element accounts for more than 16 percent of the total effect of the elements.

Our second hypothesis is that experienced investors will give a lower score to a given pitch than inexperienced investors. Recall that this hypothesis reflects the assumption that experienced investors have more precise priors. In Table 4, we restrict our attention to participants who received the null treatment. Panel A shows regressions of the judge's score on a dummy variable for whether they are experienced. We first define experience by early-stage deal volume. Experienced judges gave scores that were 2.3 points lower on average unconditionally (column $1, \mathrm{p}<0.01$ ) and 1.8 points lower with controls and order dummies included (column 2, $\mathrm{p}<0.05$ ). The size of the difference is about one-third of the standard deviation of score. When experience is defined as those who are a $\mathrm{VC}$, angel investor, or mentor, the effects are slightly larger (columns 3 and 4). These results support the hypothesis that experienced judges, by either of the definitions we use, have more precise priors. Appendix Table B3 shows that the standard deviation of judge scores do not vary substantially by experience category.

We show the average effect of pitch training on score in Table 5. The point estimate is small, negative, and statistically indistinguishable from zero (column 1). Adding order and judge dummies (column 2) and controls (column 3) does not change the picture.

The third hypothesis is that pitch training has more positive effects on the upper quantiles of score than the lower quantiles. Figure 3 presents pitch training effects from quantile regressions that include order and judge effects as well as participant controls. (Regressions are available in Appendix Table B4, Panel A.) The effects of training at the $20^{\text {th }}$ and $40^{\text {th }}$ quantiles are negative and statistically significant, with 
magnitudes of -1.53 and -104 . The effect at the $60^{\text {th }}$ percentile is -0.37 but is not statistically distinguishable from zero. The effect at the $80^{\text {th }}$ percentile is -0.10 and is also not statistically distinguishable from zero. A test using simultaneous bootstrap estimation fails to reject the null that the $80^{\text {th }}$ percentile effect is greater than the $20^{\text {th }}$ percentile effect with $p=0.04$.

The fourth hypothesis suggests the effect of training will be more positive for experienced investors than inexperienced investors. We first explore average effects. Table 6 presents separate regressions of pitch training on score for experienced and inexperienced investors including order and judge dummies as well as participant controls. Results using the early-stage deal volume measure of experience are shown first. Pitch training reduces the average score by 1.7 points for inexperienced investors (columns $1, \mathrm{p}<0.01$ ), or about 0.3 standard deviations, but has no statistically significant effect for experienced investors (column 2). The results are the same using the $\mathrm{VC} /$ angel/mentor definition of experience (columns 3 and 4). Appendix Table B5 present interacted regressions that show that the more positive effect of training on experienced judges is statistically significant at 1 percent for the deal-volume definition and at 5 percent for the VC/angel/mentor definition.

Next, we look at the effects of training across quantiles of the score distribution for experienced and inexperienced investors. We compute the effects using interacted specifications that include order and judge dummies and controls. The results are shown in Figure 4. Panel A uses the early-stage deal volume definition of experience. The estimates for experienced (high volume) judges are greater at all quantiles. The differences are statistically significant at the $20^{\text {th }}, 40^{\text {th }}$, and $80^{\text {th }}$ quantiles. The same pattern of point estimates holds for the $\mathrm{VC} / \mathrm{judge} /$ mentor definition of experience in panel $\mathrm{B}$, though the differences are statistically significant only for the $40^{\text {th }}$ and $80^{\text {th }}$ quantiles. (Quantile regressions are available in Appendix Table B4, Panels B and C.)

The results are robust to different specifications of pitch performance, and different statistical techniques. The results were also qualitatively the same when the regressions predicting these measures were ordered probits. Finally, the results were qualitatively the same when we dropped mentors, angels or 
VCs from experienced-judge measure, and were qualitatively the same when we measured experienced investors as venture capitalists or angels only.

To ensure that we were truly capturing the effects of pitch training on the key goal of an elevator pitch - to continue discussions with investors - we reran all of our analyses predicting the single item "I would pursue a follow-up meeting to learn more about the venture." All of our results are qualitatively the same when this single item is used in place of our SCORE measure.

\subsection{ALTERNATIVE MECHANISMS}

We have argued that pitch training changes judge scores via the elements participants put in their pitches. For experienced judges, training leads to positive effects on the upper quantiles of the score distribution and negative effects on the lower quantiles. For inexperienced judges, the effects are all negative. This pattern is consistent with training increasing the precision of pitches and the experienced judges having more precise priors than the inexperienced ones.

For a different mechanism to be a convincing alternative to elements as the channel through which training affects scores, it would need to produce the observed results. We consider and reject several alternative mechanisms below.

\subsubsection{Training improves venture idea quality}

An alternative mechanism for the effect of training is that training improves the quality of the participants' venture ideas. However, if training improved the quality of the participant's ideas, it would increase the pitch signal $s_{i}$. According to equation 4, training should then have a positive effect on score at all quantiles of the distribution of scores.

In Table 5, we show the effect of training on score unconditionally (column 1) and with judge and order dummies (column 2) and participant controls added (column 3). In all specifications, the point estimate is negative but is not statistically significant. Moreover, Figure 3 shows that pitch training has zero effect at the 60 th and 80th percentiles and a negative effect at the 20th and 40th percentiles. 
Furthermore, if training improves venture idea quality, we would also expect the effect of training to be independent of the priors of the judges. Therefore, we would not the expect differential training effects for experienced and inexperienced judges shown in Table 6 and Figure 5.

Finally, a positive effect on quality also fails to explain why pitch training increases the variance of the distribution of scores. One might counter that perhaps training is only effective for the most talented participants, whose ideas would naturally fall in the upper quantiles of the score distribution and which could explain why effects are only positive at higher quantiles. However, this would still not explain why we get any negative effects, nor would it explain differential effects on experienced and inexperienced judges.

\subsubsection{Pitch elements measure quality rather than elements}

One might argue that the mechanism through which pitch training operates is not to provide more precise information about the venture, but to improve venture quality in ways that only experienced investors can see. Several aspects of our study design and results suggest that this is a much less plausible explanation than the theory we presented. First, we instructed our coders to explicitly code for the presence of elements of a particular type and not to evaluate the quality of those elements. Therefore, for our measure of elements to capture dimensions of idea quality, our coders would have had to code for something other than what we asked them to identify.

Second, the measures of the elements identified by our coders had high inter-rater reliability. To measure dimensions of venture quality in similar ways, the coders would have to see those dimensions similarly. But these dimensions of venture quality could not be easy for everyone to observe. Otherwise, inexperienced investors would have to be able to see those same dimensions of quality. It seems difficult to account for why the coders could identify hard-to-notice dimensions in quality in similar ways, while inexperienced investors could not see these same dimensions of quality.

Third, if our measures of pitch elements were just proxies for unobserved quality, we should not observe a wide range of quality levels for each level of elements. Figure 5 plots our measures of idea quality and 
pitch elements from the first draft. While better quality ideas are associated with more elements overall, the correlation is quite weak. There are a wide range of quality levels for each level of elements.

\subsubsection{Training makes participants better adhere to norms of pitching}

Another alternative mechanism is that training shows participants what the norms of pitching are. By helping participants adhere to norms, they are more likely to receive high scores from judges.

This explanation is not consistent with the data. If the mechanism at work was adherence to norms, we would not expect there to be negative effects of training, which we observe for participants with low quality venture ideas. Moreover, we would expect experienced judges to be better than inexperienced judges at discounting norm adherence since the goal of evaluating a pitch is to discern the quality of the business idea and not adherence to norms. If norm adherence were the mechanism, we would expect to see more positive effects of training on inexperienced judges relative to experienced ones, when in fact we see the opposite.

Finally, to explore the norm hypothesis, we coded the videos of participant's pitches for two norms of professional behavior: whether they shake hands with the judges and whether they introduced themselves to the judges. Pitch training had no effect on either of these behaviors.

\subsubsection{Training makes participants more "likable" or confident}

A further alternative mechanism through which training might affect scores is by changing the participants or the judges' view of them. For instance, the training could make the participants more appealing to judges or more confident in their efforts, independent of the quality of their ideas. We rule out these alternative explanations in several ways.

First, the pitch training was not designed to affect likability or presenter confidence but rather effective communication of ideas. Therefore, if pitch training affected likability or presenter confidence rather than elements, its effects had to operate on something it was not intended to do and not affect something it was intended to do, an uncommon way for treatments to operate. 
Second, if pitch training did change participant likability or confidence, we would expect that effect to be consistently positive across participants. We would not expect increased likability or confidence to lead to a negative effect on score for part of the distribution, which we observe. Moreover, we would not expect a differentially positive effect on the upper quantiles of the score distribution, which we also observe. Finally, we would expect inexperienced investors to be more swayed by extraneous factors such as likability or presenter confidence than experienced investors. But, in fact the effects of training on the scoring of inexperienced investors was more negative.

Third, we coded videos of the participants for five behaviors that the prior psychological research shows are related to confidence: a comfortable pace of speaking, appearing comfortable, making eye contact, showing enthusiasm, not getting upset, and not forgetting the pitch. We sum these behaviors into an index and show that pitch training does not affect them (Table 7, column 3).

\subsubsection{Investors with less deal volume are more time constrained}

We use deal volume as one of our measures of investor experience. One might argue that lower deal volume does not represent investor experience, but rather the person's time commitment to investment activity. They have less volume because they choose to spend time on other activities than venture investing. If this were true, we would expect people with lesser deal volume to be less interested in pursuing venture opportunities that are pitched to them.

However, as we showed in Table 4 and discussed above, the opposite is true. Investors who are less experienced tend to express a greater interest in pursuing new ventures pitched to them than investors who are more experienced.

\subsubsection{Inexperienced investors are less diversified}

One might argue that inexperienced investors are more interested in pursuing venture opportunities than experienced investors because they are less diversified. If investors are risk averse, having less diversification would lead each additional venture to be more valuable to inexperienced investors than 
experienced ones. However, the desire for diversification cannot account for the effects of training being more negative for inexperienced investors than for more experienced investors, which Figure 5 indicates.

\subsubsection{Experienced investors are more likely to be venture capitalists}

One might argue that experienced investors are more likely to be venture capitalists than inexperienced investors, who are more likely to be angel investors. That is, the higher standards of venture capitalists rather than the different priors of experienced and inexperienced investors might be the reason why the experienced investors judge the ventures more harshly. However, that explanation is less consistent with the data than our theoretical explanation. We conducted regression analyses that examined each of the investor types individually and by dropping each of the investor types from the analysis. The patterns remain qualitatively same in these robustness checks as they do in the reported regressions. The data indicate that experienced judges gave lower scores, but are not more likely to be venture capitalists than inexperienced investors. The data is, thus, less consistent with the explanation that experienced judges are a type of investor with higher standards than other investors, but is consistent with the explanation that experienced investors have different priors than inexperienced investors.

\subsection{DISCUSSION}

In this study, we examined the effects of pitch training on the willingess of accredited investors to pursue investigation of early stage ventures after seeing an elevator pitch. We developed a model to show that pitch training helps in the evaluation of new venture ideas because it induces entrepreneurs to provide more elements in their pitches.

Our model predicts that the additional elements will tend to improve investors' evaluations if the quality of the idea is high and will worsen their evaluations if the perceived quality is low. The model therefore posits that pitch training will improve investors' ability to discriminate between good and bad ideas. Since

experienced investors have more precise priors than inexperienced investors, the model predicts pitch training will tend to have a more positive effect on experienced investors than inexperienced ones. 
We examined whether pitch training affects the investor evaluation of aspiring entrepreneurs' pitches in the manner predicted by the model by conducting a field experiment that randomly assigned 271 participants in four elevator pitch competitions in Northeast Ohio to pitch training or a null treatment.

The empirical results were consistent with our model. We found that (1) training increases the elements contained in pitches; (2) experienced investors give lower scores to a given pitch relative to inexperienced investors; (3) training has a more positive effect on upper quantiles of the quality distribution than lower quantiles and therefore increases the variance of scores and (4) training has a more positive effect on experienced investors at all levels of quality. On average, training had no effect on the scores of experienced investors and a negative effect on the scores of inexperienced investors.

Our results are conservative. They show that even training delivered by video in a short time without the opportunity to engage in much practice yields results.

The empirical results were inconsistent with several alternative explanations for the effect of pitch training on the willingness of accredited investors to pursue investigation of an early stage venture. The mechanism through which training works appears not to be improved venture idea quality; greater adherence to the norms of pitching; or greater entrepreneur likeability.

Our results have several implications for further research. Our study provides insight into the true causal factors that affect pitch performance, and in doing so challenges the core assumptions of the practitioner literature about the value of pitch training. The practitioner literature generally argues that pitch training is valuable because it improves the underlying quality of new ventures, increasing the odds that they will receive funding and improving the entrepreneurs' welfare. However, our experiment shows that the value of pitch training lies its effects on the provision of elements contained in pitches. By making pitches more informative, training allows experienced investors to more efficiently distinguish between good and bad venture ideas.

Our results also have implications for the practice of entrepreneurship. Many would-be entrepreneurs seek investment from external investors every year. Their elevator pitches are often a first point of entry with those financiers. Because effective pitching is necessary to continue the conversation with investors 
who may provide funding, effective pitching is important for both entrepreneurs and investors. Our results show that entrepreneurs can be trained in ways that improve the investor pitch process.

However, our results also show that pitch training is not a substitute for venture quality. Good pitching is important to investors who can better differentiate high and low quality ventures. Learning what content to include in a pitch and what style to use to deliver it is therefore valuable because it provides investors with more clarity about the venture the entrepreneur is pitching. Because pitch training does not affect the quality of the underlying venture idea, it is more valuable to entrepreneurs with high quality venture ideas than low quality ones.

Our study also points out that pitch training only works at increasing the interest of experienced investors in the better ideas. At least in the short run, learning to provide more elements in pitches does not benefit entrepreneurs on average, and, in fact, reduces the odds of success. That finding has important practical implications for entrepreneurs seeking financing from investors.

This last point has pedagogical implications. Because pitch training has a more positive effect on performance with experienced judges and a negative effect on performance inexperienced judges, wouldbe entrepreneurs who want to learn how to pitch experienced judges effectively need to pitch to, and receive feedback from, experienced judges. Given the difficulty of finding practitioners willing to help train students, academic institutions may be tempted to substitute inexperienced judges for experienced ones in pitch competitions. Our results suggest that such a strategy will undermine the benefit of pitch training by leading would-be entrepreneurs to learn lessons that will not benefit them later when they pitch experienced investors.

Our study is not without limitations. We examine only one particular type of pitch, the elevator pitch, which is typically delivered only in the very beginning of the fund raising process. Our findings may not generalize to other types of pitches delivered later in the process.

In addition, our sample consists not of experienced entrepreneurs but would-be company founders. Our findings may not generalize to experienced entrepreneurs who are pitching similar types of investors. The 
value of rudimentary pitch training might exist primarily for aspiring entrepreneurs rather than those who have done this before.

Our study is undertaken in Northeast Ohio, a region not known for having large numbers of would-be entrepreneurs or experienced investors. The average level of investor experience and quality of entrepreneurial efforts in our sample may be below that of other regions. As a result, the findings might not generalize to locales where investor experience and entrepreneurial effort quality is higher.

Nevertheless, our findings, however limited in generalizability, provide evidence that pitch training causes aspiring entrepreneurs to have better success with their elevator pitches when they are delivered to experienced investors. Those findings have value to both explaining why pitch training works and to helping would-be entrepreneurs succeed at raising money from accredited investors. 
Axtell, R 2001. Zipf Distribution of U.S. Firm Sizes. Science 293 (5536): 1818-20.

Brooks, A., Huang, L., Kearney, S. and Murray, F. 2014. Investors Prefer Entrepreneurial Ventures Pitched by Attractive Men. Proceedings of the National Academy of Sciences of the United States of America 111 (12): 4427-31.

Calderon, G., J. Cuhna, and G. Giorgi. 2013. Business Literacy and Development: Evidence from a Randomized Controlled Trial in Rural Mexico. NBER Working Paper Series 19740.

Carpentier, C., and Suret, J. 2014. Canadian Business Angel Perspectives on Exit: A Research Note. International Small Business Journal, 33(5): 582-593.

Center for Venture Research. 2016. The Angel Investor Market in 2015. Accessed July 26, 2016. https://paulcollege.unh.edu/sites/paulcollege.unh.edu/files/webform/Full\%20Year\%202015\%20A nalysis\%20Report.pdf

Chen, X., Yao, X., and Kotha, S. 2009 Entrepreneur Passion and Preparedness in Business Plan Presentations. Academy of Management Journal, 52: 199-214.

Clark, C. 2008. The Impact of Entrepreneurs' Oral 'Pitch' Presentation Skills on Business Angels Initial Screening Investment Decisions. Venture Capital, 10(3): 257-279.

Coughter, P. 2012. The Art of the Pitch. New York: Palgrave MacMillan.

Fairlie, R., Karlan, D., and Zinman, J. 2015. Behind the GATE Experiment: Evidence on Effects of and Rationales for Subsidized Entrepreneurship Training. American Economic Journal: Economic Policy, 7(2): 125-161.

Foo, Maw-Der, Poh Kam Wong, and Andy Ong. 2005. "Do Others Think You Have a Viable Business Idea? Team Diversity and Judges’ Evaluation of Ideas in a Business Plan Competition.” Journal of Business Venturing 20 (3): 385-402.

Gabaix, X., and Landier, A. 2008. Why Has CEO Pay Increased So Much? Quarterly Journal of Economics 123 (1): 49-100.

Getty, P. 2014. The 12 Magic Slides. New York: Springer. 
Hsu, H. 2004. What Do Entrepreneurs Pay for Venture Capital Affiliation?, Journal of Finance 59: 18051844.

Hsu, H. 2007. Experienced Entrepreneurial Founders, Organizational Capital, and Venture Capital Funding, Research Policy 36: 722-741.

Huang, L., and Pearce, J. 2015. Managing the Unknowable: The Effectiveness of Early-stage Investor Gut Feel in Entrepreneurial Investment Decisions. Administrative Science Quarterly, 60: 634-670.

Hudson, M. 2016. How Do You Compare to Other Angel Investors? Blog post on Angel Insights Blog. May 31, 2016 https://www.angelcapitalassociation.org/blog/how-do-you-compare-to-other-angelinvestors/. Accessed November 30, 2016.

Kaplan, S., Stromberg, P., 2004. Characteristics, Contracts, and Actions: Evidence from Venture Capitalist Analyses. Journal of Finance, 59: 2177-2210.

Karlan, D. and Valdivia, M. 2011. "Teaching entrepreneurship: Impact of business training on microfinance clients and institutions", Review of Economics and Statistics 93(2): 510-27.

Kirsch, D., Goldfarb, B., and Gera, A, 2009. Form or Substance: The Role of Business Plans in Venture Capital Decision Making. Strategic Management Journal, 30: 487-515.

Klaff, O. 2011. Pitch Anything. New York: McGraw Hill.

Levene, H. 1960. Robust Tests for Equality of Variances. In Contributions to Probability and Statistics: Essays in Honor of Harold Hotelling, ed. I. Olkin, S. G. Ghurye, W. Hoeffding, W. G. Madow, and H. B. Mann. Stanford University Press: Menlo Park, CA:pp . 278-292.

Loh, E. 2011. Response to How Do I Write An Effective Elevator Pitch? on Quora.com. Accessed July 19, 2016. https://www.quora.com/How-do-I-write-an-effective-elevator-pitch/answer/Elliot-Loh

Luttmer, E. 2007. Selection, Growth, and the Size Distribution of Firms. The Quarterly Journal of Economics $122(3):$ 1103-44.

Mandato, J. 2009. Getting to Yes: What Does a Thoughtful MedTech Investor Really Care About? The 2009 Case-Coulter Lecture at Case Western Reserve University. Online video clip accessed July 19, 2016. https://www.youtube.com/watch?v=dK6wdT1ib5Y 
Martens, M., Jennings, J., and Jennings, P. 2007. Do the Stories They Tell Get Them the Money They Need? The Role of Entrepreneurial Narratives in Resource Acquisition at IPO. Academy of Management Journal. 50(5): 1107-1132.

Mason, C. and Harrison, R. 2003. Auditioning for Money: What do Technology Investors Look for at the Initial Screening Stage? Journal of Private Equity, 6: 29-42.

Maxwell, A., Jeffrey, S., and Levesque, M. 2011. Business Angel Early Stage Decision Making. Journal of Business Venturing, 26: 212-225.

McKaskell. T. 2008. Introduction to Angel Investing. Melbourne, Aus: Breakthrough Publications.

Mitteness, C. 2012. Horse vs. Jockey?: How Stage of Funding Process and Industry Experience Affect the Evaluations of Angel Investors. Venture capital: An International Journal of Entrepreneurial Finance, 14(4), 241-267.

McGowen, W. 2015. The Pitch Perfect. New York: Harper Collins.

Moskovitz, T., Vissing-Jørgensen, A., 2002. The Returns to Entrepreneurial Investment: A Private Equity Premium Puzzle? American Economic Review 92: 745-778.

Moulton, B. 1990. An Illustration of a Pitfall in Estimating the Effects of Aggregate Variables on Micro Units. The Review of Economics and Statistics, 72: 334-338.

Nagy, B., Pollack, J., Rutherford, M., and Lohrke, F. 2012. The Influence of Entrepreneurs' Credentials and Impression Management Behaviors on Perceptions of New Venture Legitimacy. Entrepreneurship Theory and Practice 36 (5): 941-65.

National Venture Capital Association. 2016. National Venture Capital Association Yearbook 2016. Accessed July 26, 2016. http://nvca.org/?ddownload=2963

Newman, Jerry. 2015. "Power Laws in Venture." Blog post on Reaction Wheel. June 25, 2015. Accessed November 30, 2015. http://reactionwheel.net/2015/06/power-laws-in-venture.html

Parhankangas, A., and Ehrlich, M. 2014. How Entrepreneurs Seduce Business Angels: An Impression Management Approach. Journal of Business Venturing, 29 (4): 543-64. 
Rose, D. 2014. Angel Investing: The Gust Guide to Making Money and Having Fun Investing in Startups. New York: John Wiley and Sons. 
Figure 1: Investor's Decision Tree

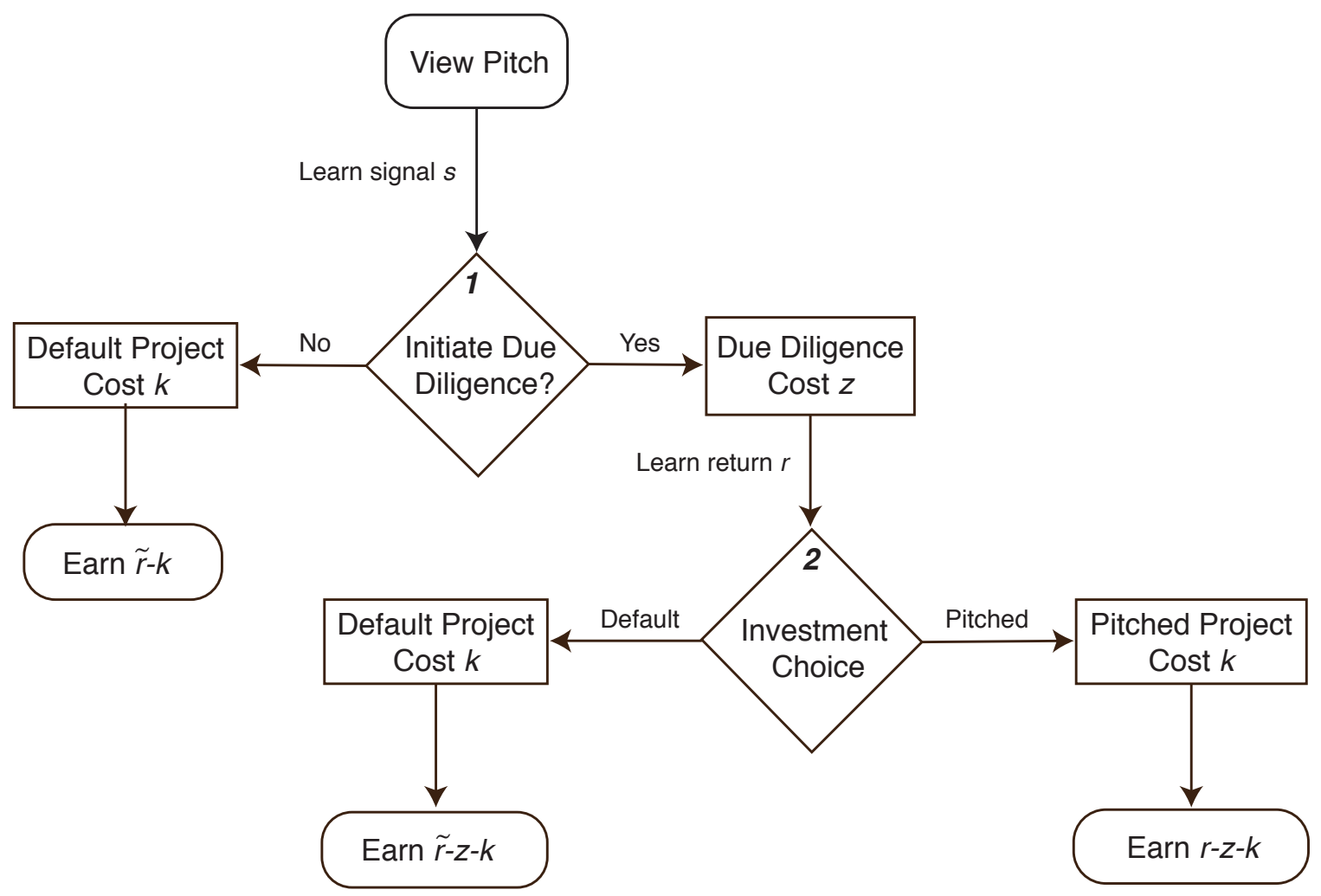


Figure 2: Effect of Pitch Elements on Option Value

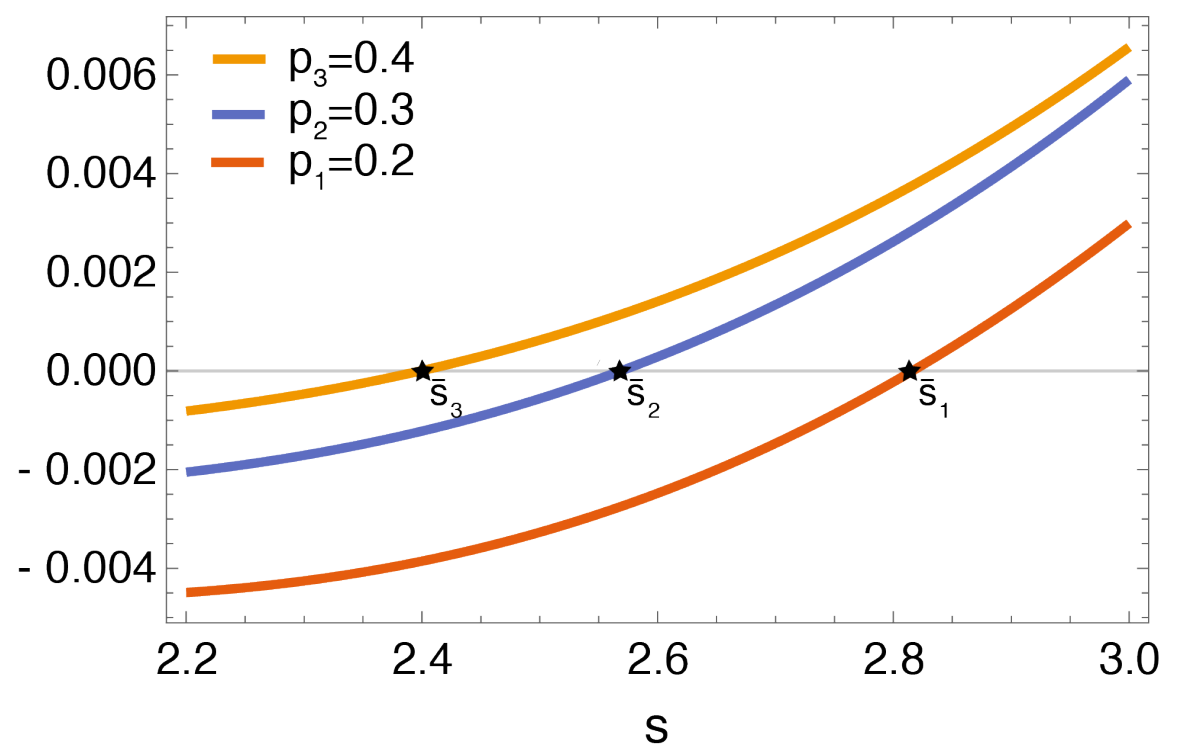

Notes: The figure plots the partial derivative $\frac{\partial v}{\partial \ell}$ for three values of the prior precision $p_{1}, p_{2}$, and $p_{3}$. The values of $\bar{s}$ corresponding to these values are shown with stars. The plots set $k=2.33, \lambda=1 / 10, \ell=10$, and $\tilde{r}=2.66$. 
Figure 3: Effects of Pitch Training on Score by Quantile

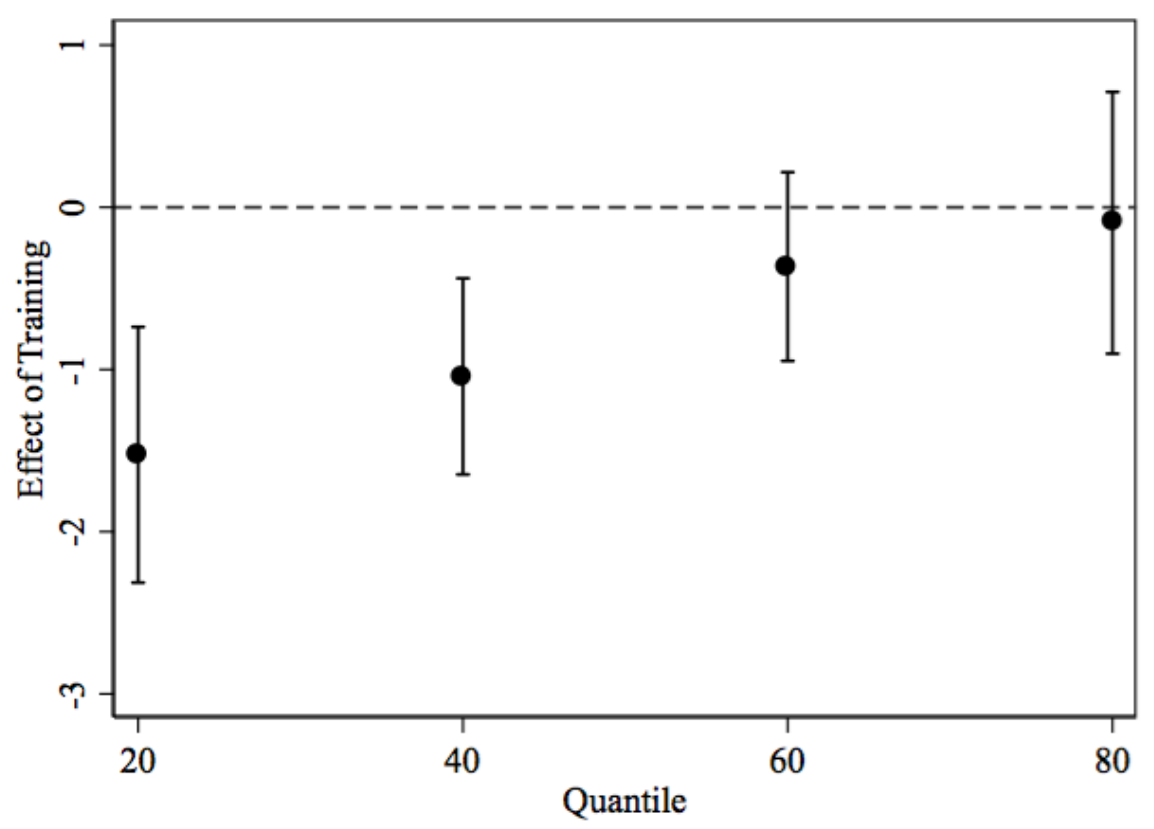

Notes: The graph show treatment effects on quantiles of the score distribution with $95 \%$ confidence intervals. The effects are estimated using quantile regressions of score on pitch training, controls, and judge and order dummies. Controls include first draft elements, whether pitched before, experience operating a business, gender, whether a graduate student, and university affiliation. 
Figure 4: Effects of Pitch Training on Score by Quantile and Judge Experience

Panel A: Experience Defined As High Early-Stage Deal Volume

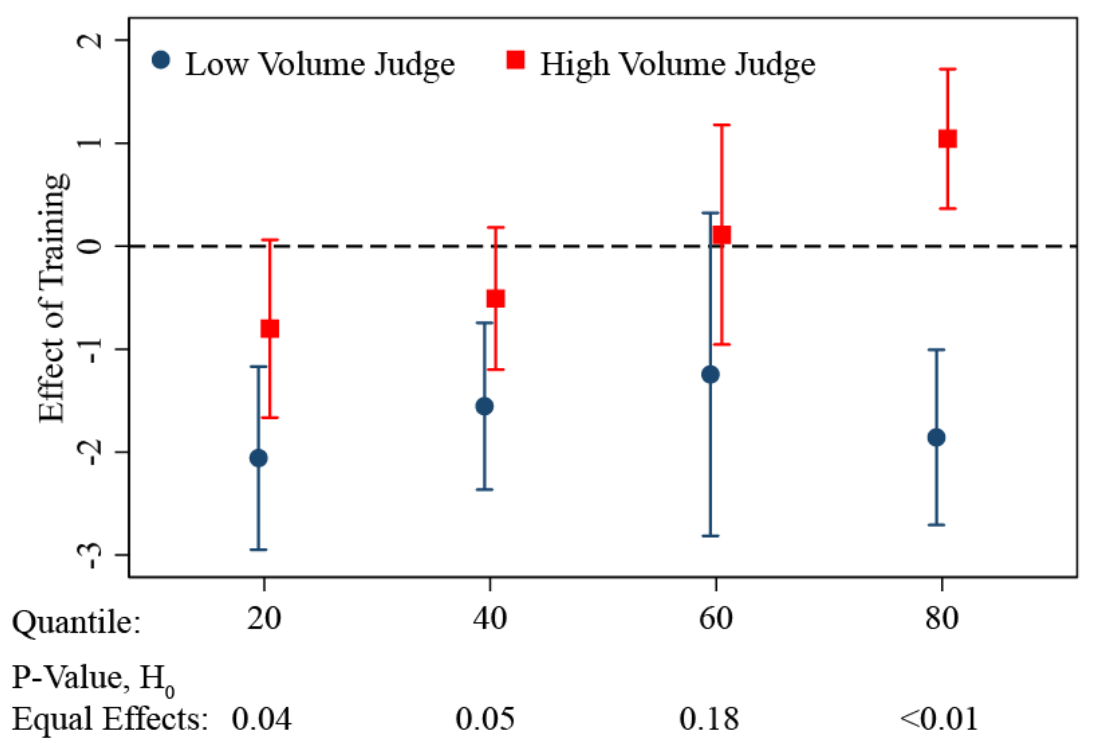

Panel B: Experience Defined As Being a VC, Angel Investor, or Mentor

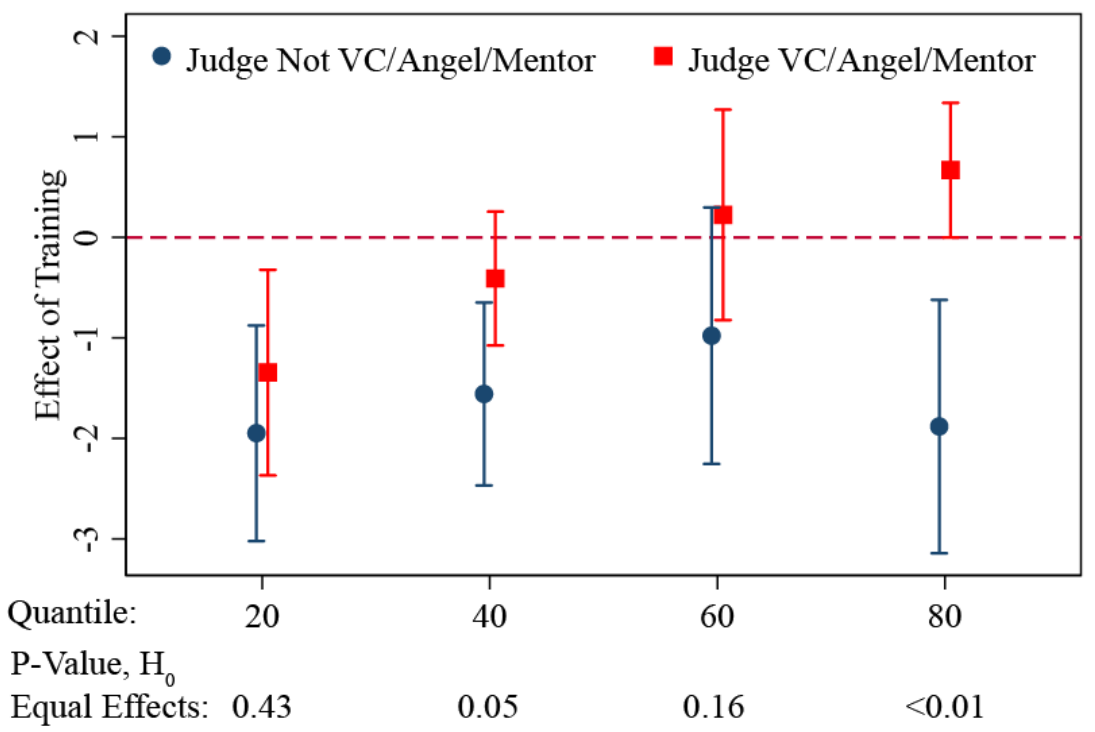

Notes: Graphs show treatment effects on quantiles of the score distribution with $95 \%$ confidence intervals. The effects are estimated using quantile regressions of score on pitch training, and interaction between pitch training and experience, controls, and judge and order dummies. Controls include first draft elements, whether pitched before, experience operating a business, gender, whether a graduate student, and university affiliation. Panel dummies indicate the panel of judges to which a participant pitched. Order dummies indicate randomly assigned pitch order. 
Figure 5: Idea Quality and Pitch Elements

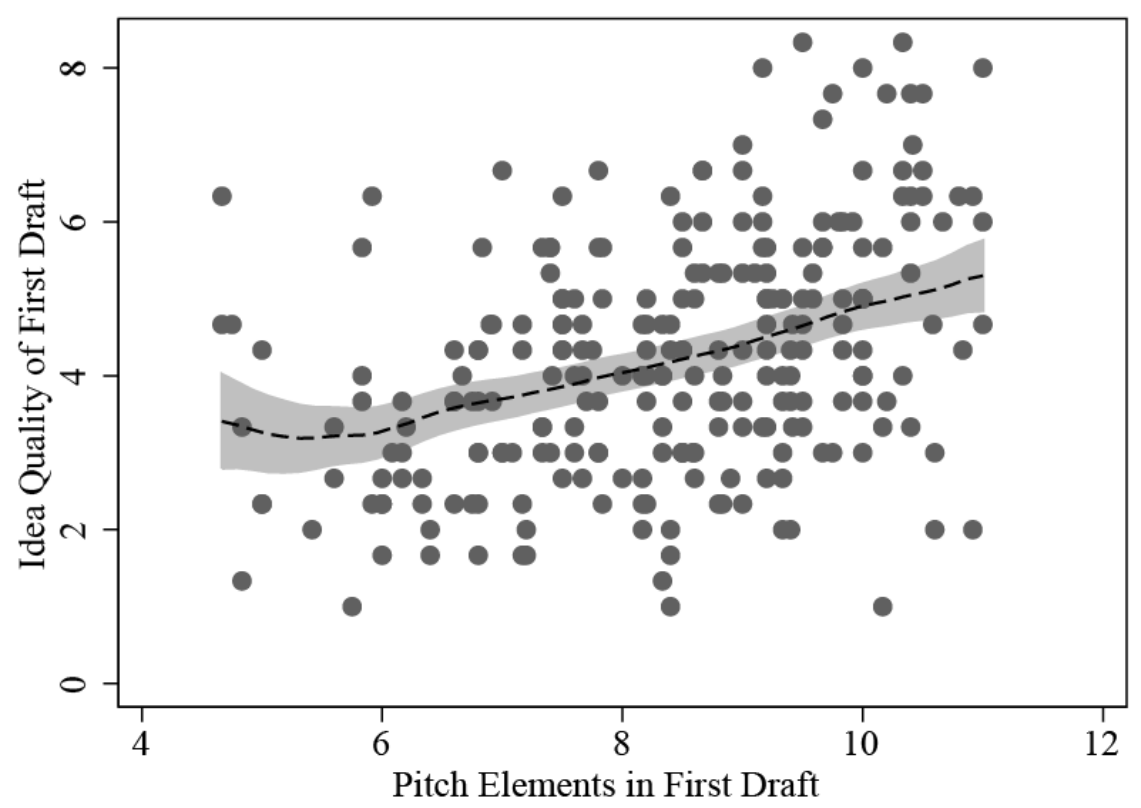

Notes: The plot shows pitch elements and idea quality based on participants' first drafts The line is a local-linear regression and the shaded region shows 95\% confidence intervals for the predicted value. Results are similar using residuals from regressions of the variables on controls and panel and order dummies. 
Table 1. Treatments and Training Groups

\begin{tabular}{|c|c|c|c|}
\hline Treatment & $\begin{array}{l}\text { Training } \\
\text { Group }\end{array}$ & $\begin{array}{c}\text { Pitch Concepts } \\
\text { Covered }\end{array}$ & Training Methods \\
\hline \multirow[t]{3}{*}{ NULL } & 1 & Basic & \\
\hline & 2 & Basic + Content & Theory \\
\hline & 3 & Basic + Style & Theory + Example \\
\hline \multirow{3}{*}{$\begin{array}{r}\text { PITCH } \\
\text { TRAINING }\end{array}$} & & & \\
\hline & 4 & Basic + Content & Theory \\
\hline & 5 & Basic + Style & Theory + Example \\
\hline
\end{tabular}


Table 2. Descriptive Statistics

\begin{tabular}{|c|c|c|c|c|c|}
\hline Participants, $N=271$ & Mean & SD & $\begin{array}{l}\text { Mean } \mid \\
P T_{i}=1 \\
(\mathrm{~N}=216)\end{array}$ & $\begin{array}{l}\text { Mean } \mid \\
P T_{i}=0 \\
(\mathrm{~N}=55)\end{array}$ & $\begin{array}{l}\text { Equality } \\
\text { of Means, } \\
P \text {-value }\end{array}$ \\
\hline Age & 22.7 & 5.8 & 22.5 & 23.6 & 0.26 \\
\hline Female & 0.32 & & 0.32 & 0.33 & 0.95 \\
\hline White & 0.56 & & 0.57 & 0.55 & 0.78 \\
\hline Asian & 0.25 & & 0.24 & 0.26 & 0.88 \\
\hline Pitched Before & 0.29 & & 0.29 & 0.29 & 0.99 \\
\hline Has Existing Business & 0.17 & & 0.16 & 0.20 & 0.52 \\
\hline Idea Quality in First Draft & 4.22 & 1.66 & 4.24 & 4.16 & 0.73 \\
\hline Pitch Elements in First Draft & 8.25 & 1.91 & 8.25 & 8.27 & 0.93 \\
\hline Graduate Student & 0.26 & & 0.26 & 0.27 & 0.83 \\
\hline Studies STEM Field & 0.36 & & 0.36 & 0.33 & 0.65 \\
\hline One or More Entrepreneurship Classes & 0.50 & & 0.50 & 0.47 & 0.70 \\
\hline One or More Business Classes & 0.63 & & 0.63 & 0.64 & 0.90 \\
\hline CWRU Student & 0.49 & & 0.49 & 0.49 & 0.98 \\
\hline Kent Student & 0.18 & & 0.18 & 0.16 & 0.72 \\
\hline JCU Student & 0.20 & & 0.19 & 0.24 & 0.46 \\
\hline Judges, $\mathrm{N}=50$ & Mean & SD & & & \\
\hline Years Since College & 26.8 & 12.0 & & & \\
\hline Female & 0.14 & & & & \\
\hline MBA & 0.40 & & & & \\
\hline Lawyer & 0.18 & & & & \\
\hline Venture Capitalist & 0.18 & & & & \\
\hline Angel Investor & 0.22 & & & & \\
\hline Mentor & 0.28 & & & & \\
\hline VC/Angel/Mentor & 0.54 & & & & \\
\hline Active Entrepreneur & 0.16 & & & & \\
\hline Listed as Investor in Crunch Base & 0.36 & & & & \\
\hline Positive Exit in CrunchBase & 0.26 & & & & \\
\hline High Volume of Early Stage Deals & 0.52 & & & & \\
\hline Interacts With Students & 0.18 & & & & \\
\hline Biomedical Operating Exp. & 0.22 & & & & \\
\hline Software Operating Exp. & 0.18 & & & & \\
\hline CWRU Affiliate & 0.26 & & & & \\
\hline
\end{tabular}

Notes: Equality of means p-values are from two-sample t-tests. 
Table 3: Final Draft Elements on Pitch Training

(1)

(2)

(3)

\begin{tabular}{lccc}
\hline Pitch Training & $0.57^{* *}$ & $0.59^{* *}$ & $0.56^{* *}$ \\
& $(0.26)$ & $(0.27)$ & $(0.22)$ \\
Constant & $8.80^{* * *}$ & & \\
& $(0.24)$ & & \\
\hline$N$ & 0.01 & 0.01 & 0.32 \\
Adjusted R & 271 & 271 & 271 \\
Controls & $\mathrm{N}$ & $\mathrm{N}$ & $\mathrm{Y}$ \\
Pitch Panel, Order Dummies & $\mathrm{N}$ & $\mathrm{Y}$ & $\mathrm{Y}$ \\
DV Mean & 9.25 & 9.25 & 9.25 \\
\hline
\end{tabular}

Notes: Standard errors are robust. Stars indicate statistical significance of tests of the null hypothesis that the coefficient is zero: * mean $p<0.10 ; * *$ means $p<0.05$; and $* * *$ means $p<0.01$. Controls include first draft elements, whether pitched before, experience operating a business, gender, whether a graduate student, and university affiliation. Panel dummies indicate the panel of judges to which a participant pitched. Order dummies indicate randomly assigned pitch order. 
Table 4: Regressions of Score on Judge Experience in the Null Treatment

\begin{tabular}{|c|c|c|c|c|}
\hline & \multicolumn{2}{|c|}{$\begin{array}{c}\text { Experience Defined As } \\
\text { High Early-Stage Deal } \\
\text { Volume }\end{array}$} & \multicolumn{2}{|c|}{$\begin{array}{l}\text { Experience Defined As } \\
\text { Being a VC, Angel } \\
\text { Investor, or Mentor }\end{array}$} \\
\hline & $(1)$ & $(2)$ & (3) & (4) \\
\hline Experienced Judge & $\begin{array}{l}-2.29 * * * \\
(0.84)\end{array}$ & $\begin{array}{r}-1.84 * * \\
(0.81)\end{array}$ & $\begin{array}{l}-3.31 * * * \\
(0.83)\end{array}$ & $\begin{array}{l}-2.37 * * * \\
(0.88)\end{array}$ \\
\hline Constant & $\begin{array}{l}16.07 * * * \\
(0.71)\end{array}$ & & $\begin{array}{l}16.69 * * * \\
(0.70)\end{array}$ & \\
\hline$N$ & 182 & 182 & 182 & 182 \\
\hline Adjusted $\mathrm{R}^{2}$ & 0.04 & 0.24 & 0.08 & 0.26 \\
\hline Controls & $\mathrm{N}$ & $\mathrm{Y}$ & $\mathrm{N}$ & $\mathrm{Y}$ \\
\hline Order Dummies & $\mathrm{N}$ & Y & $\mathrm{N}$ & $\mathrm{Y}$ \\
\hline DV Mean & 14.88 & 14.88 & 14.88 & 14.88 \\
\hline
\end{tabular}

Notes: Standard errors are corrected for clustering at the participant level. Stars indicate statistical significance of tests of the null hypothesis that the coefficient is zero: * mean $p<0.10$; ** means $p<0.05$; and $* * *$ means $p<0.01$. Controls include first draft elements, whether pitched before, experience operating a business, gender, whether a graduate student, and university affiliation. Order dummies indicate randomly assigned pitch order. 
Table 5: Score on Pitch Training

\begin{tabular}{llll} 
& $(1)$ & $(2)$ & $(3)$ \\
\hline Pitch Training & -0.43 & -0.56 & -0.61 \\
& $(0.66)$ & $(0.54)$ & $(0.47)$ \\
Constant & $14.88^{* * *}$ & & \\
& $(0.59)$ & & \\
\hline $\mathrm{N}$ & 897 & 897 & 897 \\
Adjusted R & 0.00 & 0.24 & 0.33 \\
Controls & $\mathrm{N}$ & $\mathrm{N}$ & $\mathrm{Y}$ \\
Order, Judge Dummies & $\mathrm{N}$ & $\mathrm{Y}$ & $\mathrm{Y}$ \\
DV Mean & 14.54 & 14.54 & 14.54 \\
\hline
\end{tabular}

Notes: Standard errors are corrected for clustering at the participant level. Stars indicate statistical significance of tests of the null hypothesis that the coefficient is zero: * mean $p<0.10$; ** means $p<0.05$; and *** means $p<0.01$. Controls include first draft elements, whether pitched before, experience operating a business, gender, whether a graduate student, and university affiliation. Judge dummies indicate identity of randomly assigned judge. Order dummies indicate randomly assigned pitch order. 
Table 6: Regressions of Score on Pitch Training By Judge Experience

\begin{tabular}{|c|c|c|c|c|}
\hline & \multicolumn{2}{|c|}{$\begin{array}{l}\text { Experience Defined As High } \\
\text { Early-Stage Deal Volume }\end{array}$} & \multicolumn{2}{|c|}{$\begin{array}{c}\text { Experience Defined As } \\
\text { Being a VC, Angel Investor, } \\
\text { or Mentor }\end{array}$} \\
\hline & $\begin{array}{c}\text { Inexperienced } \\
\text { (1) }\end{array}$ & $\begin{array}{l}\text { Experienced } \\
\text { (2) }\end{array}$ & $\begin{array}{c}\text { Inexperienced } \\
\text { (3) }\end{array}$ & $\begin{array}{c}\text { Experienced } \\
\text { (4) }\end{array}$ \\
\hline Pitch Training & $\begin{array}{l}-1.72 * * * \\
(0.58)\end{array}$ & $\begin{array}{c}0.44 \\
(0.60) \\
\end{array}$ & $\begin{array}{l}-1.72 * * * \\
(0.57)\end{array}$ & $\begin{array}{c}0.40 \\
(0.62)\end{array}$ \\
\hline$N$ & 438 & 459 & 414 & 483 \\
\hline Adjusted $\mathrm{R}^{2}$ & 0.35 & 0.31 & 0.37 & 0.29 \\
\hline Controls & $\mathrm{Y}$ & $\mathrm{Y}$ & $\mathrm{Y}$ & $\mathrm{Y}$ \\
\hline Order, Judge Dummies & $\mathrm{Y}$ & $\mathrm{Y}$ & $\mathrm{Y}$ & $\mathrm{Y}$ \\
\hline DV Mean & 14.87 & 14.24 & 15.29 & 13.91 \\
\hline
\end{tabular}

Notes: Standard errors are corrected for clustering at the participant level. Stars indicate statistical significance of tests of the null hypothesis that the coefficient is zero: * mean $p<0.10$; ** means $p<0.05$; and $* * *$ means $p<0.01$. Controls include first draft elements, whether pitched before, experience operating a business, gender, whether a graduate student, and university affiliation. Judge dummies indicate identity of randomly assigned judge. Order dummies indicate randomly assigned pitch order. 
Table 7: Alternative Mechanisms

\begin{tabular}{lccc}
\hline & $\begin{array}{c}\text { Shake } \\
\text { Hands } \\
(1)\end{array}$ & $\begin{array}{c}\text { Introduced } \\
\text { Self } \\
(2)\end{array}$ & $\begin{array}{c}\text { Confident } \\
(3)\end{array}$ \\
\hline Pitch Training & 0.01 & -0.02 & -0.19 \\
& $(0.04)$ & $(0.06)$ & $(0.14)$ \\
\hline$N$ & 270 & 270 & 270 \\
Adjusted R ${ }^{2}$ & 0.03 & 0.13 & 0.04 \\
Controls & $\mathrm{Y}$ & $\mathrm{Y}$ & $\mathrm{Y}$ \\
Pitch Panel, Order Dummies & $\mathrm{Y}$ & $\mathrm{Y}$ & $\mathrm{Y}$ \\
DV Mean & 0.09 & 0.76 & 3.43 \\
\hline
\end{tabular}

Notes: Standard errors are robust. Stars indicate statistical significance of tests of the null hypothesis that the coefficient is zero: * mean $p<0.10$; ** means $p<0.05$; and $* * *$ means $p<0.01$. Controls include first draft elements, whether pitched before, experience operating a business, gender, whether a graduate student, and university affiliation Panel dummies indicate identity of randomly assigned panel. Order dummies indicate randomly assigned pitch order. 